\title{
Do Texto à Cena
}

Daniel Furtado Simões da Silva

Resumo

\begin{abstract}
A partir das noções de tradução e de transtextualidade examinamos a transposição de textos literários de Caio Fernando Abreu para a cena teatral. Essa transposição estrutural e estilística configura diferentes regimes da narratividade, que implicam em deslocamentos do eixo da narrativa teatral, a qual se apóia alternadamente em vários sistemas semiológicos à disposição do encenador.
\end{abstract}

Palavras-chave: Caio Fernando Abreu. Tradução intersemiótica. Texto cênico. Regime de narratividade.

Ao longo deste ensaio, examinamos algumas questões que surgem quando da tradução de um texto literário para um espetáculo teatral, observando características e possibilidades decorrentes da passagem da linguagem escrita para o palco. Essa tradução é um processo que se move entre semelhanças e diferenças e que aponta, por um lado, para a autonomia dos produtos finais - texto e encenação -, e, por outro, para a dependência do processo de tradução quanto às características, às singularidades e aos objetivos de cada uma dessas concretizações artísticas.

A discussão sobre o que norteia a tradução intersemiótica realizada nessa passagem ${ }^{1}$, através da concretização do espetáculo teatral, se dá através da análise de espetáculos que tem como hipotexto ${ }^{2}$ contos e novelas de Caio Fernando Abreu: Pela noite, dirigido por Marcos Marinho, baseado na novela homônima, publicada originalmente no livro Triângulo das águas; Rua das flores, dirigido por Tarcísio Ramos Homem, inspirado no conto "Réquiem para um fugitivo", do livro O ovo apunhalado; e Os dragões não conhecem o paraíso, dirigido por Kalluh Araújo, que utilizou fragmentos de vários textos de Caio Fernando Abreu.

Examinando a trajetória literária do referido autor, desde seu primeiro livro, Inventário do irremediável, publicado em 1970, até Ovelhas negras, de 1995, o último que veio a público quando o escritor ainda era vivo, e incluindo aqueles lançados após sua morte, em 1996, dois aspectos das narrativas ficam claros. Primeiro, a íntima relação entre as experiências vividas por Caio e seus textos. Em entrevista concedida em 1970, Caio Fernando Abreu afirmava possuir uma "paixão doida por existir", e, por força dessa paixão, não se recusava nenhuma experiência, sem se furtar a "expressar cruamente essas experiências" (TROSS, 1970, p. 3) no seu trabalho. Essa relação, o 
ato de expressar nas narrativas o que foi experienciado, configura-se quase como um trabalho de registro, fato que o próprio Caio expressou com clareza:

Penso no escritor sempre como fotógrafo do seu tempo, embora não tenha essa preocupação deliberada com a contemporaneidade do texto. Sinto-me extremamente comprometido com as coisas que a minha geração conheceu. Vivi os anos 50, o existencialismo, o movimento beatnik. Mas vivi também, graças a Deus, o movimento hippie, profunda e sonhadoramente. Então, no momento em que a minha literatura tem uma marca forte da contracultura, é porque ela fatalmente está definida por essas experiências. (ABREU, 1996).

O segundo aspecto é a emoção que seus textos carregam, que as palavras de Lygia Fagundes Telles, no prefácio à primeira edição de $O$ ovo apunhalado, de 1975, expressam com propriedade:

O que me inquieta e me fascina nos contos de Caio Fernando Abreu é essa loucura lúcida, essa magia de encantador de serpentes que, despojado e limpo, vai tocando sua flauta e as pessoas vão-se aproximando de todo aquele ritual aparentemente simples, mas terrível porque revelador de um denso mundo de sofrimento. De piedade. De amor. (TELLES, 1984, p. 13)

O trabalho de conferir sinceridade e emoção aos textos - ao mesmo tempo que fotografa o seu tempo e reflete experiências que não são apenas pessoais mas comuns a toda uma geração - , leva Caio a ser apontado como "biógrafo da emoção", subtítulo de um fascículo editado, em 1988, pelo Instituto Estadual do Livro do Rio Grande do Sul, sobre sua vida e obra. Os críticos da obra de Caio Fernando Abreu destacam o caráter marcadamente urbano das narrativas e o anonimato e a fragmentação das personagens. Ordinariamente, os protagonistas são seres solitários e abandonados, e sua inserção nos meios sociais não se dá através de laços afetivos profundos e permanentes. Essa temática, centrada na fragmentação e na incompletude das relações mantidas pelas personagens, cujo universo existencial se caracteriza por uma carência ou, antes, por uma indigência afetiva e por um conflito com as normas sociais, está presente na maior parte da obra de Caio Fernando Abreu.

Estes aspectos irão se refletir no texto cênico dos espetáculos analisados. O texto cênico é pensado aqui como o conjunto analisável de signos que compõem a encenação, a qual está baseada na materialidade desses signos, o que faz com que as qualidades inerentes ao objeto sejam incorporadas ao processo de significação. Em um espetáculo de teatro, a ficcionalidade que a representação estabelece coexiste com a realidade dos corpos. A percepção é feita paralela e concomitantemente nesses dois níveis, o ficcional e o concreto, que é material e sensorial.

Neste processo de tradução, o encenador escolhe qual o meio, qual a matéria mais adequada para transmitir um determinado estado, sensação ou imagem. Ele vai se apoiar ora no texto dito pelos atores, ora na evolução de seus corpos pelo espaço, ora nas imagens criadas pela relação dos objetos e corpos no espaço, numa sucessividade que institui diferentes regimes de narratividade. As relações entre os vários sistemas que compõem a cena, relações essas que podem ser de coordenação ou subordinação, criam diferentes maneiras de conduzir a narrativa. O regime de narratividade instituído pelo espetáculo depende daquilo que o meio escolhido oferece, como meio material, em termos visuais, sonoros e mesmo culturais, que acarreta e pressupõe o estímulo aos sentidos, e que determina tanto a produção como a recepção sígnica.

Para levarmos a cabo essa análise, adotaremos o modelo proposto por Coelho Neto para o estudo semiológico do teatro, concernente ao que nós chamamos aqui de 
texto cênico. Este texto é constituído em primeiro nível pela personagem, pelo cenário e pelo jogo: personagem, nesse caso, pode ser entendido como os atores, mas não apenas os atores - mesmo porque nem sequer é necessário que sejam pessoas -, mas seres ou objetos investidos de uma máscara; cenário é o espaço trabalhado e determinado para a cena, mesmo que seja um espaço vazio; jogo é um certo relacionamento envolvendo os atores e o cenário onde atuam, ou o conjunto de regras determinantes desse relacionamento. Cenário e personagem precisam ter existência material, física e real, e o Jogo será uma relação que se desenvolve no tempo e no espaço (Cf. COELHO NETO, 1980, p. 21-30).

Outro conceito importante para desenvolvermos nossa exposição é o de vetorização, termo proposto por Pavis. A vetorização é um processo que consiste em associar e conectar os signos entre si, percebendo-os ligados como em redes: o signo cria seu sentido na dinâmica que o liga aos outros, sintetizando as opções de atuação, as escolhas dramatúrgicas e as linhas de força da representação, mantendo ainda aberta a possibilidade de polissemia dos significantes (PAVIS, 2003, p. 13).

Cada uma das montagens, colocadas em perspectiva, permite o aprofundamento de um aspecto teórico distinto. Em Pela noite optou-se por seguir a seqüência narrativa proposta por Caio Fernando Abreu na novela homônima. Nesta, acompanhamos o périplo de dois homens pela cidade de São Paulo, iniciando e terminando no apartamento de um deles. Em torno da novela e do espetáculo há duas questões fundamentais: a primeira é o tempo e sua passagem, que são centrais na novela de Caio; a outra é que essa narrativa está vinculada a um regime da palavra, ou seja, é a palavra, o texto dito pelos atores, o principal elemento condutor da narrativa teatral.

Quanto ao tempo, o título já nos remete a ele: Pela noite, durante ela, atravessando-a. A própria idéia de noite já traz em si algo de temporal, de uma duração e de algo que passa. Na novela, o fluxo do tempo é marcado pelos relógios, que constantemente lembram aos protagonistas e ao leitor essa passagem. Ao efêmero que a contagem das horas e dos minutos traz à mente, Caio contrapõe as lembranças e a memória. A tentativa de fixação do passado através da memória surge como um ato de superação do tempo, ou de tentar conter a dissolução das coisas e das relações.

A encenação não trata desse embate entre o fugaz e o que permanece da mesma forma que a novela. Quase todas as marcas temporais, os recuos ao passado através de memórias e lembranças, não são incorporadas ao texto proferido pelos atores durante o espetáculo, por se tratar, na novela, de pensamentos das personagens. Esses pensamentos não são comunicados ao leitor através dos diálogos, e são apenas estes, os diálogos, que a adaptação utiliza, transformando-os em fala. O texto cênico suprime ainda os marcadores da passagem do tempo - os relógios -, que dão a idéia de fluxo e de fugacidade, assim como aquelas referências que nos permitem identificar a cidade onde se passa a ação como sendo São Paulo. A ausência, na encenação, das pausas descritivas, dos textos não-dialógicos que permeiam a narrativa de Caio Fernando Abreu, torna o espetáculo mais "acelerado" e "objetivo". O próprio ritmo da fala dos atores é utilizado com esse fim. A sua gestualidade - cujo desenho e cuja definição ultrapassam ou diferem daquele gesto que é feito cotidianamente - nos remete a uma dança, havendo inclusive uma incorporação dos passos de um tango, que finaliza o espetáculo, na movimentação.

Neste espetáculo há uma dependência narrativa dos outros sistemas semióticos em relação ao signo lingüístico, uma subordinação ao texto dito em cena: os outros 
sistemas são elaborados e constituídos em relação semântica com as falas dos atores. Se é verdade que tradicionalmente cabe ao texto dito pelos atores um lugar de destaque, senão o principal, no entendimento das situações e relacionamentos desenvolvidos no palco, isto não elimina o fato de que essa configuração corresponde a uma opção dramatúrgica e estética. Pérsio começa a falar sobre seu "bode com cheiro de merda" justamente na hora em que ele e Santiago começam a comer, contrariando o proposto pelo texto de Caio Fernando Abreu e causando um certo estranhamento, talvez mesmo um desconforto em parte da assistência. Quando Pérsio se refere à moça dos sapatinhos vermelhos do conto de Andersen, Santiago coloca um dos pés sobre a cadeira, mostrando claramente seu sapato, também vermelho, e criando uma analogia que não existia no texto de Caio. O ato de comer do prato do outro, de um lamber o prato onde o outro comeu, reforça o significado proposto pelo texto, de superação do nojo e penetração na intimidade alheia. Essas ações e o momento de sua execução estão relacionados com o texto dito pelos atores, são contrapostos a ele, criam sua significação em função do significado que as palavras veiculam, alterando-o, negando-o ou complementando-o.

Esse tipo de narrativa, determinada ou conduzida através da palavra, pelos significados que ela traduz ou sugere, é talvez o mais freqüente nas encenações que encontramos no teatro, porém não é o único. Rua das flores é um espetáculo que não usa o código verbal. Isso determina que a atribuição de sentidos seja feita por outros sistemas semióticos, que, nos espetáculos teatrais, normalmente dividem com a linguagem verbal essa função: a imagem e os códigos visuais que a montagem utiliza são alçados à função de guia da narrativa. No caso de Rua das flores, uma encenação que podemos classificar como de dança-teatro, a imagem visual tem como elemento base o corpo dos intérpretes, seu movimento e sua evolução no espaço. A alternância de estados de tensão e relaxamento dos corpos, as diferenças imprimidas na qualidade de movimento, o deslocamento espacial, o seu ritmo e fluência, são decodificados pelos espectadores como relações entre personagens, atitudes e desejos.

No que toca ao conto, destacamos dois aspectos: o primeiro é a solidão, presentificada no protagonista e na sua relação com a mãe e o anjo; relação baseada na interdição e no silêncio: o narrador se proíbe de olhar para o anjo - "não ousava encará-lo" - e entre ele e a mãe impera a distância:

Embora não nos falássemos, ela sempre foi muito educada, muito gentil. Não lembro de tê-la ouvido falar alguma vez em voz baixa ou terna, ou mesmo em qualquer outra voz. Mas isso não importa: o essencial é que ela nunca gritou. E se é verdade que não chegamos a ter amor um pelo outro, é verdade também que não chegamos a ter ódio. Acredito mesmo que tivéssemos descoberto a forma ideal de convivência e comunicação. (ABREU, 2001, p. 22).

Essa não-relação entre o narrador e sua mãe, o silêncio que vigora entre eles é transformado e transmitido no espetáculo pelo não-olhar: a mãe não olha para o seu filho, é uma comunicação sem-comunicação, que sintetiza a ausência de afeto entre eles. O segundo é o espaço simbólico do conto, tematizado e construído pela imagem da casa, do guarda-roupa e pela relação triangular da mãe-anjo-filho, na qual por vezes o anjo se encarrega de suprir a ausência paterna, mesmo que em sonho. Este espaço concretiza-se na encenação através do palco quase vazio, ocupado apenas pelo guarda-roupa. Essa ausência de elementos referenciais confere uma maior abstração ao espaço cênico: o palco nu contém todos os espaços possíveis, bastando que o ator, através do seu gesto ou da palavra, abra o caminho para a imaginação do espectador. Ao mesmo tempo acentua a atuação de outros elementos como a luz, que reconfigura 
o espaço cênico através da utilização de cores, da intensidade e do posicionamento dos focos de luz.

O corpo do bailarino se incumbe de demonstrar as características das personagens, através das qualidades de esforço imprimidas e dos fatores que conduzem o movimento - o peso, a fluência, o espaço e o tempo. As alterações nessas dinâmicas acarretam mudanças na atmosfera da cena e nas atitudes das personagens, mesmo sem o estabelecimento de um sentido unívoco de correspondência entre um e outro. A linguagem corporal não atua apenas para completar ou contradizer o significado das palavras, mas assume o papel de condutora do espetáculo, tanto em suas funções cognitivas quanto poéticas, contando com a participação de outros sistemas semióticos, em especial a iluminação e a música. Se a utilização da corporeidade e do movimento torna a fábula mais imprecisa, fazendo com que a história se dilua em função de uma pluralidade de sentidos, isso, de fato, é o que se espera diante da linguagem escolhida.

Já Os dragões não conhecem o paraíso não usa como hipotexto um dos contos ou novelas de Caio Fernando Abreu, mas recorre a uma parte expressiva de sua obra. $O$ texto dramatúrgico criado é uma apropriação de vários textos de Caio, num trabalho de recorte que impõe sobre as narrativas originais uma nova visão, fruto de uma percepção e um entendimento específico do universo ficcional elaborado pelo escritor, e que se cristaliza em um novo texto, pré-cênico. Nesse processo há uma seleção e manipulação dos textos que visa não à manutenção de um "sentido original", daquilo que poderia ser percebido nos contos, mas sim à criação de um novo sentido. Há um tomar posse que enxerga nos textos os motivos ou recorrências que coadunam com a visão pretendida, com os sentidos que o encenador lhes enseja conferir na montagem.

Paralelamente a essa construção do texto dramatúrgico, o eixo narrativo se transfere do corpo ou da palavra para a imagem criada no palco e para o papel que as personagens desempenham em cada quadro/cena. A lógica do espetáculo é a que Hans Meyerhoff chama de lógica das imagens, na qual eventos passados, presentes e futuros são relacionados e fundidos uns aos outros. Essa lógica é a que ampara o método de livre associação e do monólogo interior, e que exibe uma estrutura que é casualmente determinada por "associações significativas". Essas imagens provocam reverberações e repercussões que não passam necessariamente pela compreensão racional (Cf. MEYERHOFF, 1976, p. 21).

O lado menos luminoso, a atmosfera opressiva, ao mesmo tempo repressora e permeada de transgressões, que percebemos em vários dos contos de Caio, perpassa toda a encenação, que se norteia por uma visão apocalíptica, discutindo a solidão humana, a existência e a relação do homem com Deus. A interpretação, assim como os figurinos, não se preocupa em seguir uma estética realista. O cenário, sem um referencial concreto, não nos remete a nenhum lugar específico. A iluminação transforma o espaço, e é marcante a presença do som como elemento constituinte da imagem cênica. Criam-se cenas quase autônomas, centradas na visualidade e desenvolvendo uma situação que não se prolonga no quadro seguinte.

Não há, na peça, a preocupação com o delineamento psicológico das personagens, sua função no espetáculo não é determinada por seu caráter. O aspecto semiótico é colocado em relevo não apenas por aquilo que a personagem diz, mas por sua relação (inclusive espacial) com as outras personagens e com os outros elementos presentes na cena. Tornam-se actantes, uma força, uma possibilidade de processo (definimos actante, aqui, como tudo que atua, que sustenta ou promove uma proposição). Destaca-se ainda a possibilidade de um clímax mesmo numa estrutura 
que não está vinculada a um desenvolvimento lógico-linear da ação, mas baseada num crescendo no impacto das imagens, cujo ápice é decerto a chuva que encerra o espetáculo.

O texto cênico criado a partir do texto literário revela as potencialidades tanto da narrativa literária como do próprio fazer teatral. Há uma relação estreita entre a própria estrutura do texto literário e a configuração da encenação. As encenações surgem como hipertextos da obra de Caio Fernando Abreu, repercutindo-a ao explorar um determinado aspecto do universo criado por seus contos. Se relações de subordinação e/ou coordenação criadas entre os vários sistemas semióticos que compõem a encenação criam diferentes regimes de narrativa cênica (o que chamei aqui de narratividade), o diálogo estabelecido entre os textos literário e cênico permite que certos aspectos da estrutura de ambos se tornem mais claros, assim como certos delineamentos temáticos e estilísticos configurados tanto no hipotexto como no hipertexto. Além disso, a discussão sobre os regimes de narratividade assumidos pelo espetáculo propõe uma maneira clara de analisar as opções feitas pelo encenador no processo de tradução intersemiótica, e assim revelar a relação entre o eixo narrativo escolhido para a encenação e as possibilidades que o texto literário oferece.

Notas

$\prod_{1}$

No processo de conceituação da tradução, partimos de alguns teóricos que analisaram a tradução interlingual, em especial Haroldo de Campos - que relacionava o ato de traduzir com o de criar, visando o que chamava de "efeito icônico do todo" (CAMPOS, 1981, p. 81) -, até chegar à tradução intersemiótica, cujo conceito, de transcriação de formas baseada na equivalência das diferenças, tomo emprestado a Julio Plaza (PLAZA, 2003).

${ }^{2}$ Gérard Genette define transtextualidade como tudo aquilo que coloca um texto em relação com outros textos, seja de forma manifesta ou oculta. A hipertextualidade, um dos tipos de transtextualidade, é a relação que une um texto B (hipertexto) a um texto anterior A (hipotexto). Assim, o hipertexto é um texto derivado de um anterior, seja por transformação simples, seja por imitação. O texto cênico dos espetáculos analisados deriva-se de textos literários de Caio Fernando Abreu. (Cf. GENETTE, 1982, p. 7-14)

Abstract

From the concepts of translation and textuality, we examine the transposition of Caio Fernando Abreu's literary texts to theatrical scene. This structural and stylistic transpositions configure distinct narrativity systems, which implicates in displacement of theatrical narrative axis, that is supported alternating by some of semiological systems on director's disposal.

Key words: Caio Fernando Abreu. Intersemiotic translation. Performance text. Narrativity system.

Referências

ABREU, Caio Fernando. O ovo apunhalado: contos. Porto Alegre: L\&PM, 2001.

ABREU, Caio Fernando. Triângulo das águas, novelas. Rio de Janeiro: Nova Fronteira, 1983. 
ABREU, Kill. Eu quero biografar o humano do meu tempo. $O$ Estado de S. Paulo. São Paulo, 27 ago. 1996.

AUTORES GAÚCHOS. Um biógrafo da emoção. In: Caio Fernando Abreu. Porto Alegre: IEL, 1988, vol. 19, p. 03-8.

CAMPOS, Haroldo de. Deus e o diabo no Fausto de Goethe. São Paulo: Perspectiva, 1981.

COELHO Netto, J. T. Em cena, o sentido. São Paulo: Duas

Cidades, 1980.

GENETTE, Gérard. Palimpsestes. Paris: Éditions du Seuil, 1982.

MEYERHOFF, Hans. O tempo na literatura. São Paulo: McGrawHill do Brasil, 1976.

PAVIS, Patrice. A análise dos espetáculos. São Paulo: Perspectiva, 2003.

PLAZA, Júlio. Tradução intersemiótica. São Paulo: Perspectiva, 2003.

TELLES, Lygia Fagundes. Prefácio. In: ABREU, Caio F. O ovo apunhalado. Rio de Janeiro: Salamandra, 1984. p. 13-14.

TROSS, Sérgio. Não estou satisfeito com nada do que escrevi. Suplemento Literário do Minas Gerais. Belo Horizonte, p. 3-4, 15 ago. 1970. 